\title{
Editorials
}

\section{The interface between anaesthesia and emergency medicine}

Ten years ago, the Association of Anaesthetists of Great Britain and Ireland published a document outlining the role of anaesthetists in the emergency service. ${ }^{1}$ Despite a wide range of activities, in most hospitals the main interface between the two specialties was in the emergency management of a patient's airway. Anaesthetic assistance would generally be sought for any airway intervention beyond the most basic and specifically in the presence of airway compromise or when drugs needed to be administered to facilitate tracheal intubation. Similarly, with a range of "time critical" conditions other specialists were called to assist; cardiologists would deal with patients suffering from an acute myocardial infarction, physicians with the acute asthmatic patients while surgeons resuscitated trauma patients. Such working practices had their origins in the casualty departments of the 1960s, where the medical staff were often "supervised" by other specialties, for example, orthopaedic surgeons, whom were often little more than absentee landlords as a result of a lack of sessional allocation and with little experience or interest in dealing with medical admissions. ${ }^{2}$

The past 15 years has witnessed a dramatic change in the specialty of emergency medicine. The development of a structured training programme, fellowship examination and intercollegiate faculty, have produced a breed of emergency physicians who now manage most time critical conditions within their own departments. At a time when increasing emphasis is placed upon the importance of early and effective airway management of all major emergencies (ATLS, ALS, APLS), emergency physicians are now looking at extending their airway management skills, which will inevitably mean the administration of anaesthetic agents and muscle relaxants to facilitate tracheal intubation. ${ }^{34}$ Delays in obtaining anaesthetic assistance ${ }^{45}$ the relative inexperience of the responding anaesthetist ${ }^{6}$ and the fact that some emergency physicians may have greater experience of dealing with patients' airways in these circumstances have also accelerated moves towards greater responsibility. Finally, emergency physicians see their counterparts in the USA and Australia, performing advanced airway interventions, including the administration of drugs to facilitate intubation. ${ }^{7}$

This has caused concern among some anaesthetists, who are of the opinion that advanced airway management including the use of drugs to facilitate tracheal intubation in the emergency department is highly likely to be complicated; patients may have a full stomach, be unable or unwilling to provide any medical history, or have trauma complicating airway management. Therefore, only those with the most experience should perform rapid sequence induction and intubation. Furthermore, it is known that the reported incidence of failed and difficult intubations in the emergency department ${ }^{78}$ is approximately three times greater than seen in the operating theatre ${ }^{9}{ }^{10}$ and the equipment to deal with such events may not always be immediately available. ${ }^{11}$ Finally, even if intubation is successful who is going to take over the management of such a patient, who may require continuing anaesthesia?

Does this dilemma threaten the interface between the two specialties or is there a solution? My personal beliefs are; firstly, we have to abandon the idea that "rapid sequence intubation" equates with airway management. Trainees must be taught the assessment and airway management of a critically ill patient. This includes decision making and accepting responsibility. Secondly, it is less important who manages these patients, but the competence with which they do so. By default, emergency physicians will have to deal with this problem with increasing frequency. Changes in the working practices of anaesthetists of all grades will result in increasing difficulty obtaining experienced assistance. In recognition of this, the Faculty of Emergency Medicine have identified that in future, all emergency physicians will need to acquire the necessary skills to manage a patient's airway for the initial 30 minutes after admission. In some instances this will require the administration of drugs to facilitate tracheal intubation safely. Finally, it is important not to try to turn emergency physicians into anaesthetists, but instead equip them with the skills they need for their own environment and the problems they face. ${ }^{12}$ Audit of all of these processes will be mandatory to ensure that training is adequate and appropriate.

Laudable as such aims may be, how do we achieve them? One suggestion is that the doctors working in emergency medicine would benefit from a substantive post as an anaesthetic SHO. ${ }^{13}$ While this may provide training in airway management, it is less likely to provide experience in assessment and management of critically ill patients unless a period in critical care is included. Unfortunately, the availability of such posts has diminished recently as they have been absorbed into local rotations. The value of such posts is not universally accepted, while some suggest a need for "ring-fenced" posts in anaesthesia linked to emergency medicine, ${ }^{14}$ others have expressed the view that efforts should be directed towards ensuring anaesthetic support in the emergency department, ${ }^{15}$ a view supported by some who see airway management as a collaborative responsibility. ${ }^{16}$

For many trainees in emergency medicine, experience to fulfil training requirements will only be available in the form of an anaesthetic secondment into a supernumerary post for three to six months. If this is the case, they must be offered the opportunity of learning assessment and management of the airway in the critically ill patient. This will mean not just watching countless patients being anaesthetised for elective surgery, but time training and experience in the intensive care. Clearly defined competencies must also be identified in order to equip them to face the problems in their own unique environment. The current basic skills, listed in trainees' logbooks are insufficient. All of this must mean closer cooperation between the two specialties, starting at collegiate and extending down to departmental level. Other recent developments, for example the Emergency Airway Management Course ${ }^{17}$ may have a place. This teaches the fundamentals of induction of anaesthesia, intubation and management of the difficult airway but is based on American practice. Although it may offer the opportunity to introduce trainees to the subject, the techniques and skills learnt must be in accordance with UK practice otherwise this could lead to conflict between emergency physicians, anaesthetists and intensivists. 
Apart from initial training, of at least equal importance is the problem of maintenance of skills. Although some individuals working in large departments may have the opportunity to practise their skills on a regular basis, and thereby remain competent, many in smaller units will not. Regular short secondments within anaesthesia are a good idea, but in practice may be difficult to organise and cannot guarantee that individuals will encounter the type of situations from which they would benefit.

In the UK, one area that has been particularly slow to develop is the use of high fidelity simulators, due predominantly to both the high capital and revenue costs. As well as being used to facilitate learning and maintenance of the range of isolated technical skills management of entire clinical scenarios can be practised. In anaesthesia they have been shown to improve crisis management, speed of response and precision in following guidelines. ${ }^{18} 19$ All skills and events can be tailored to each individual's requirements, for example ranging from the routine of planned induction of anaesthesia to the very rare, but life threatening situation of "can't intubate, can't ventilate". These events can be repeated and practised endlessly without any risk to patients. Such training opportunities would require close cooperation between the anaesthetic and emergency medicine departments, to achieve maximum benefit to both specialties. The recent introduction of less expensive simulators such as the Laerdal SimMan (Laerdal Medical Ltd UK) may lead to such facilities becoming increasingly available in the near future.

Anaesthetists have to accept that in the future, on many occasions, airway management in the emergency department will be the remit of emergency physicians. If as anaesthetists, we wish to influence and guide this group towards what we perceive as best practices, then rather than putting up barriers, we should be building bridges to strengthen the interface between our specialties. It would be sadly ironic if all the areas of cooperation were jeopardised by our inability to recognise the opportunity that lies ahead.

CARL L GWINNUTT

Department of Anaesthetics, Hope Hospital, Salford M6 8HD, UK (gwinnuttcl@ukgateway.net)

1 The role of the anaesthetist in the emergency service. London: The Association of Anaesthetists of Great Britain and Ireland, 1991.

Anonymous. How should accident and emergency departments be run? BMF 1979;2:1051-3.

3 Beale JP, Graham CA, Thakore SB, et al. Endotracheal intubation in the accident and emergency department. F Accid Emerg Med 2000;1 17:439.

4 Butler J, Clancy M, Robinson N, et al. An observational survey of emergency department rapid sequence intubation. Emerg Med $\mathcal{f}$ 2001;18:343-8.

Teale KFH, Selby IR, James MR. General anaesthesia in accident and emergency departments. $\mathcal{F}$ Accid Emerg Med 1995;12:259-61.

emergency departments. F Accid Emerg Med 1995;12:259-61.
Walker A, Brenchley J. Survey of the use of rapid sequence induction in the Walker A, Brenchley J. Survey of the use of rapid sequence induction in the
accident and emergency department. F Accid Emerg Med 2000;17:95-7.

7 Sackles JC, Laurin EG, Rantapaa AA, et al. Airway management in the emergency department: a one-year study of 610 tracheal intubations. Ann Emerg Med 1998;31:325-32.

8 Tayal VS, Riggs RW, Marx JA, et al. Rapid-sequence intubation at an emergency medicine residency: success rate and adverse events during a two-year period. Acad Emerg Med 1999;6:31.

9 Crosby ET, Cooper RM, Douglas MJ, et al. The unanticipated difficult airway with recommendations for management. Can f Anaesth 1998;45:75776.

10 Benumof JL. Management of the difficult adult airway. Anaesthesiology 1991;75:1087-10.

11 Morton T, Brady S, Clancy M. Difficult airway equipment in English emergency departments. Anaesthesia 2000;55:485-8.

2 Carley S, Gwinnutt CL, Butler J, et al. Rapid sequence intubation in the emergency department: a strategy for failure. Emerg Med $\mathcal{f}$ (in press).

13 Anaesthetic training for accident and emergency trainees: an opportunity wasted. Boyle A. Anaesthesia 1999;54:1122-3.

14 Chadwick IS, Foëx BA. Anaesthetic training for trainees in accident and emergency medicine. Anaesthesia 2000;55:301-2

15 Taylor IR. Anaesthetic training for trainees in accident and emergency medicine. Anaesthesia 2000;55:302.

16 Graham CA, Munro PT. Airway management in the accident and emergency department. Anaesthesia 2000;55:814.

17 Walls RM, Luten RC, Murphy MF, eds. Manual of emergency airway management. Philadelphia: Lippincott Williams and Wilkins, 2000.

8 Chopra V, Gesink BJ, De Jong J, et al. Does training on an anaesthesia simulator lead to improvement in performance? Br f Anaesth 1994;73:293-7.

19 Asbury AJ. Simulators for general anaesthesia. Br f Anaesth 1994;73:285-6.

\section{Improving the care of the seriously ill patient: the interface between the accident and emergency department and critical care areas}

If you were suddenly taken ill with an acute medical condition where would you go, and who would you like to have treat you? In the UK, acutely ill patients are usually sent, taken, or self refer themselves to the nearest accident and emergency (A\&E) department. There, in the current climate of healthcare provision, they will be attended to in an inconsistent manner. ${ }^{1}$

Ignoring here the valuable contribution that nurses make in the $\mathrm{A} \& \mathrm{E}$ department and considering only medical care, ideally a consultant in A\&E medicine will see the patient immediately. However, often it may be a trainee from one of the acute specialties, and only some hours later. It is possible that this variability in practice costs lives because of inexperience in appreciating how sick a patient is, despite a plethora of warning signs.

Here I am dying of a hundred good symptoms.

Alexander Pope, English poet 1688-1744.

The initial treatment given by these on call trainees, as well as being delayed, may also be suboptimal, even though evidence is accumulating that early, and appropriate, treatment along physiological lines in the emergency room can have a long term positive effect on outcome. ${ }^{2}$
How can this scenario be improved? The two key elements are education and multi-specialty, as well as multi-professional, working patterns by which senior clinicians see and supervise the care of such patients.

The treatment benefits from a formal, but prompt, assessment of serious conditions such as major trauma and myocardial infarction are now appreciated. The use of protocols is helpful and, working within a defined framework of care or "use of a common language of care" as seen in major trauma, ensures all know what is expected. Progress is now being made in expanding the experience gained in these areas to caring for the seriously ill patient in general.

It is recognised that there are a number of problems that need to be tackled. The interfaces between the ICU, HDU, A\&E, MAU and the medical on take team are often unclear. ${ }^{1}$ The Royal College of Physician's Working Party on the Interface between Intensive Care and Emergency Medicine, which is to be published later this year, has heard repeatedly of the problems in $A \& E$ departments. Specifically, the large number of medical emergencies is causing difficulties because of a shortage of doctors and beds. The introduction of MAUs is recognition of the fact that seriously ill patients are best grouped together where 
scarce nursing and medical resources can be concentrated. A number of models exist, but MAUs seem to work best when senior medical staff become involved early and where there are close links with the critical care areas, ideally including shared appointments and rotations of trainees between these areas and specialties.

For the intensivist, a phrase used because there seems to be no better, this is good news. For many years the ICU consultant, usually anaesthetist but now often physician, when called to see a sick patient has often despaired of the care provided by trainees on the ward before referral. ${ }^{3}$ This has been shown repeatedly to be attributable to a failure to appreciate the seriousness of the situation and refer upwards to senior colleagues. As David Goldhill observed "Intensive care is only one episode in the continuum of care for the patient ..., treatment and decision making in the ER, OR, or on the ward may well be important [in determining the patient's survival]". ${ }^{4}$

Comprehensive Critical Care intends to address these problems. ${ }^{5}$ Its publication was a seismic event in the world of intensive care medicine; the consequences have yet to be appreciated by many clinicians. Essentially the message is "The right care in the right place at the right time given by the right people". This should be the message from the Department of Health's current deliberations on access to urgent and unscheduled healthcare.

To fulfil the aims of Comprehensive Critical Care the National Patients' Access Team is pushing forward an ambitious programme of education and service development. Their goal is to improve access, experience of and outcomes for patients with potential or actual need for critical care. This requires a hospital-wide approach to early identification and assessment of critically ill patients. Historically, when called to the wards, intensivists have generally become involved with patients (usually surgical) late in the course of their acute illness. This will change. Although few ICUs have the manpower at the moment, with the introduction of outreach services, nurse consultants ( $50 \%$ of whose time is for education), and the planned expansion in consultants with an interest in intensive care medicine, the goal is improve care hospital wide; the concept of "the ICU without walls".

To drive these changes locally each Trust should now have a Critical Care Delivery Group. ${ }^{6}$ This committee should be chaired by the chief executive or their nominated representative from the Trust Board and will include a consultant from the A\&E department.

However, it remains vital that doctors acquire the fundamentals of recognition and care of the seriously ill patient early on in their career. Ideally this is done under supervision in the clinical environment. Unfortunately the opportunities for this to occur may be relatively infrequent for individual trainees, who now spend much less time caring directly for patients. There are a number of didactic courses available to aid this process; ideally they should be targeted at undergraduate and PRHO level.

Eventually, however, one can only hope that the Working Group on Modernising the SHO Grade, chaired by Professor Liam Donaldson, the chief medical officer, will agree that all trainees must rotate through posts where they can be taught these "critical" skills before they need to be put into unsupervised practice.

Until that time, senior clinicians in A\&E departments and critical care areas should continue to work together to improve the early care of the seriously ill medical patient. Such collaborative working has been successful in trauma. A number of such initiatives are now in place, for example, in Edinburgh, Norwich, Whipps Cross and Whiston Hospitals. We should learn from their experiences and continue to press for the necessary increase in the number of senior doctors in emergency medicine and critical care that will be required. I firmly believe all now recognise this need.

PETER NIGHTINGALE

Intensive Care Unit, Wythenshawe Hospital, Southmoor Road, Wythenshawe, Manchester M23 9LT, UK (pnightingale@compuserve.com)

1 Federation of Medical Royal Colleges. Acute medicine: the physician's role. London: June 2000.

2 Rivers EP, Ander DS, Powell D. Central venous oxygen saturation monitoring in the critically ill patient. Curr Opin Crit Care 2001;7:204-11.

3 McQuillan P, Pilkington S, Allan A, et al. Confidential inquiry into quality of care before admission to intensive care. BMF 1998;316:1853-8.

4 Goldhill DR, Sumner A. Outcome of intensive care patients in a group of British intensive care units. Crit Care Med 1998;26:1337-45.

5 Department of Health. Comprehensive critical care: the review of adult critical care services. London: Department of Health, May 2000.

6 Modernising critical care services. Health Service Circular 2000/017. 


\section{Anaphylaxis: quintessence, quarrels, and quandaries}

Anaphylaxis is the quintessence of emergency medicine. It occurs unexpectedly often in the young and otherwise healthy, ${ }^{1}$ may progress rapidly from an innocuous presentation, is potentially fatal particularly if mistreated, has no bedside diagnostic test of value mandating pure clinical recognition, responds dramatically to treatment (adrenaline (epinephrine)), and usually allows discharge within six to eight hours in the absence of a biphasic response. ${ }^{2}$

When the Project Team of the Resuscitation Council (UK) first published their consensus guidelines on the Emergency medical treatment of anaphylactic reactions aimed exclusively at first medical responders, inexperienced in the management of this emergency, ${ }^{3}$ they drew the customary howls of dissent that seem to beset all reasonable attempts to define good medical practice in the treatment of acute anaphylaxis. ${ }^{4}$ The same happened after Fisher published his excellent paper on Treatment of acute anaphylaxis in the British Medical fournal, ${ }^{5}$ which was followed by no less than 10 letters in response, many of which contained errors of logic. ${ }^{2}$ More pertinently in these days of evidence-based guidelines, the Project Team of the Resuscitation Council (UK) were justifiably criticised for failing to reference in their original paper recently published emergency department guidelines. ${ }^{4}$ However, these latter guidelines themselves were simply another group of experts' own opinions, with no published data on how, when or where this other group's anaphylaxis treatment algorithms had been "clinically tested". ${ }^{6}$ Certainly, the paucity of any significant prospective, double blind, placebo controlled trials of treatment in acute anaphylaxis necessitates resorting in the main to Expert Opinion (EO) levels of evidence, but they should be recognised as such for what they are. This is beginning to change with valid papers for instance now showing that the intramuscular route of injection for adrenaline is preferable to the subcutaneous, ${ }^{7}$ and that adding $\mathrm{H}_{2}$ blockers to $\mathrm{H}_{1}$ antagonists results in the additional improvement of certain cutaneous outcomes for patients presenting with acute allergic syndromes. ${ }^{8}$

The changes to the original consensus guidelines published in this edition of the journal followed a meeting between representatives of the Project Team, the British National Formulary (BNF) and of the Department of Health $(\mathrm{DOH})$ representing the community nurses. ${ }^{9}$ The revised paper now specifies adult and paediatric management guidelines for community nurses tailored to the single preferred drug that they may administer namely adrenaline (fig 3 and 4). There are small changes to the dose and dilution of adrenaline in children plus a modification of the age brackets to align with recommendations from the Royal College of Paediatrics and Child Health (fig 2). These changes, although clinically inconsequential, will achieve consistency across both the paediatric literature and in the $\mathrm{BNF}$ and the new versions of the Green Book to be published by the $\mathrm{DOH}$ in relation to immunisation and vaccination. Figure 1 also mentions the role of an EpiPen, for those familiar with its use.

These new algorithms are clear, sensible, safe and simple. They should be available to all first responders from paramedics to general practitioners, from community nurses to non-specialist doctors in outpatient clinics, either as wall charts or laminated, pocket memos. Specialists such as emergency physicians, anaesthetists or intensivists who deal with anaphylaxis in high dependency, monitored areas will prefer to continue to use the other published guidelines referred to in the paper, which sensibly recommend the intravenous route of adrenaline in acute severe anaphylaxis, highly diluted and titrated to response. Clinicians looking for international guidelines may also wish to read the offerings from the Joint Task Force on Practice Parameters in the USA representing the American Academy, College and Joint Council respectively of Allergy, Asthma and Immunology ${ }^{10}$ and the International Resuscitation Guidelines 2000-a Consensus on Science. $^{11}$

Without now wishing to be branded a hypocrite and become just another dissenting voice, the only statement in the new Project Team guidelines that is questionable is the recommendation to halve the dose of adrenaline in patients taking amitriptyline, imipramine, or $\beta$ blockers. This is based on the theoretical potentiation of response to adrenaline in patients taking these antidepressants caused by the inhibition of the membrane pump mechanism responsible for the uptake of noradrenaline at adrenergic neurons; and to the predominance of unopposed $\alpha$ adrenergic effects leading to hypertension, bradycardia and augmented mediator release in patients taking $\beta$ blockers given adrenaline. ${ }^{12}$ Paradoxically, other authors actually recommend an increased dose of adrenaline for anaphylaxis in patients taking $\beta$ blockers. ${ }^{13}{ }^{14}$ There are no prospective, clinical data to support either viewpoint. The alternative is to attempt to increase intracellular cyclic AMP independently of the $\beta$ receptor by using glucagon intravenously in patients taking $\beta$ blockers. ${ }^{214}$

This is the ultimate quandary regarding the treatment of acute anaphylaxis. It is time for clinicians to stop arguing and to divert their energy to producing outcome data. Even if we only start with retrospective analytical studies, it would pave the way for more reasoned scientific debate and ultimately good, prospective Level 1 data perhaps from collaborative research. Until then, guidelines such as these should be followed.

ANTHONY F T BROWN

Department of Emergency Medicine, Royal Brisbane Hospital, Brisbane, Queensland 4029,_Australia (tony_brown@health.qld.gov.au)

1 Bochner BS, Lichtenstein LM. Anaphylaxis. N Engl f Med 1991;324:178590

2 Brown AFT. Therapeutic controversies in the management of acute anaphylaxis. f Accid Emerg Med 1998;15:89-95.

3 Project Team of the Resuscitation Council (UK). Emergency medical treatment of anaphylactic reactions. F Accid Emerg Med 1999;16:243-7.

4 Gavalas M, Walford C, Sadana A, et al. Medical treatment of anaphylaxis. $\mathcal{F}$ Accid Emerg Med 2000;17:152.

5 Fisher M. Treatment of acute anaphylaxis. BMF 1995;311:731-3.

6 Gavalas M, Sadana A, Metcalf S. Guidelines for the management of anaphylaxis in the emergency department. F Accid Emerg Med 1998;15:968 .

7 Simons FER, Roberts JR, Gu X, et al. Epinephrine absorption in children with a history of anaphylaxis. $\mathcal{F}$ Allergy Clin Immunol 1998;101:33-7.

8 Lin RY, Curry A, Pesola GR, et al. Improved outcomes in patients with acute allergic syndromes who are treated with combined $\mathrm{H}_{1}$ and $\mathrm{H}_{2}$ antagonists. Ann Emerg Med 2000;36:462-8.

9 Project Team of the Resuscitation Council (UK). Update on the emergency medical treatment of anaphylactic reactions for first medical responders and for community nurses. Emerg Med f 2001:18:393-5.

10 Joint Task Force on Practice Parameters. The diagnosis and management of anaphylaxis. F Allergy Clin Immunol 1998;101:S465-528.

11 International Guidelines 2000 for CPR and ECC. A Consensus on Science. Part 8: Advanced Challenges in Resuscitation. Section 3: Special Challenges in ECC. 3D: Anaphylaxis. Resuscitation 2000;46:285-8.

12 Raebel MA. Potentiated anaphylaxis during chronic beta-blocker therapy. Drug Intell Clin Pharm 1988;22:720-7.

13 Levy JH, Levi R. Diagnosis and treatment of anaphylactic/anaphylactoid reactions. Monogr Allergy 1992;30:130-44.

14 Hollingsworth HM, Giansiracusa DF, Upchurch KS. Anaphylaxis. f Intens Care Med 1991;6:55-70. 


\section{Position statements}

\section{What are they?}

Currently there are a number of ways through which clinicians may be made aware of important issues - by journals, conferences, working parties and the minutes of organisations. This varied route of communication coupled with the large number of specialties with whom emergency medicine works may mean that important messages are not received by those most affected. Positions statements offer the means for the Faculty and Association to make clear and concise statements both to those inside and outside the specialty regarding education, training, research, service or any other area of direct concern to the specialty of emergency medicine.

\section{Why do we need them?}

Position statements will be used to clarify the specialty's viewpoint in areas that range from the undisputed to the controversial. Such statements would help individual clinicians when seeking, for example, resources for further equipment (for example, end tidal $\mathrm{CO}_{2}$ monitoring) and service delivery (for example, all patients requiring computed tomography should be scanned within two hours). Also, such statements could provide a clear view of the specialty's aspirations (for example, rapid sequence intubation is to become a central skill for all future practitioners of emergency medicine). Where there is uncertainty, a statement to that effect and a call for research into that area would be another way to use position statements.

How do we disseminate such statements?

Position statements will be disseminated using the following means:

- by the minutes of both the FAEM and the BAEM

- by publication in the Emergency Medicine fournal.

- by publication on the BAEM/FAEM web site
- at the annual conferences of both organisations

- by mailing those parties who the specialty would anticipate would have a direct interest in the position statement.

\section{How do we use them?}

Position statements may be used in the following ways:

(1) As a recommendation from the authoritative bodies on all aspects of emergency medicine. Such statements may be used to argue for appropriate levels of equipment or other resources to deliver care to emergency department patients.

(2) To give clear responses to challenging reports or organisations, for example, the recent Royal College of Surgeons' document on the management of head injuries. (3) To identify areas of uncertainty (for example, should emergency physicians be trained in the use of ultrasound) and suggest ways forward (for example, commission systematic reviews, encourage research).

How do we generate position statements?

Any member or fellow wishing to develop a position statement will need to do the following:

(1) Draft the position statement

(2) Give clear justification

(3) Provide a review of the evidence

Such statements should be sent to the office of the Faculty of Accident and Emergency Medicine and will then be forwarded for consideration by the boards of both the FAEM and the BAEM. If the statement is adopted it will be disseminated as described and there will be a review date by which the proposer of the position statement must be prepared to review the latest literature.

$M$ J CLANCY

Research Committee, FAEM

\section{Position statement number 1}

\author{
Confirmation of endotracheal tube placement with \\ end tidal $\mathrm{CO}_{2}$ detection \\ The correct placement of an endotracheal tube is vital. \\ Independent confirmation of correct tube placement by \\ the use of devices that detect end tidal $\mathrm{CO}_{2}$ is mandatory \\ for every endotracheal intubation performed in the
}

emergency department and as part of the assessment of all patients who arrive at the emergency department already intubated.

Date: March 2001

Review: March 2003 